Insight

\title{
Syndromes of Production in Agriculture: Prospects for Social-Ecological Regime Change
}

\author{
John H. Vandermeer ${ }^{1}$ and Ivette Perfecto ${ }^{2}$
}

\begin{abstract}
Agricultural syndromes of production can be recognized in both historical and contemporary times. Recent literature in ecology focuses on alternative ecological states and the tipping points that may separate them, suggesting a point of view that "regime" changes will happen at those points. In agricultural ecosystems the idea of a regime is equivalent to a syndrome of production and there is no reason not to expect that regime switches will occur when tipping points are reached. Using very minimal qualitative models of economic and ecological forces, it is shown that the basic structure of regime change expected in natural ecosystems might be also expected in agroecosystems. In particular structures of nonlinearity suggest alternative syndromes and the potential for catastrophic shifts resulting from small changes in driving conditions. Furthermore, relaxing the assumption of monotonicity reveals the potential for such catastrophic shifts resulting from stochastic forces or chaotic dynamics, even in the absence of changes in driving conditions.
\end{abstract}

Key Words: agriculture; production syndromes; regime change; stability

\section{INTRODUCTION}

The transformation of agriculture has been a continuous process ever since its invention, multiple times, thousands of years ago. Much as with other technological issues, such transformations are sometimes slow in coming, sometimes fast, sometimes simple and obvious, sometimes complicated and obscure. A detailed accounting, either historically situated or restricted to contemporary operation is challenging to say the least. Yet there are clearly modes and tempos that are discernible, longue durée, so to speak, within which a kind of socio-technological homeostasis can be recognized (Braudel 1984, Wallerstein 2001). Such quasi equilibria are frequently punctuated by dramatic changes, ruptures in the discourse, such that the system begins operating in a completely different fashion approaching an alternative quasi equilibrium. This historical framework has inadvertently taken its place in contemporary ecology (Beddoe et al. 2009) where there is much interest in the issue of regime change, the welldocumented tendency of ecosystems that may appear to be quite stable and homeostatic to suddenly change dramatically into a completely different state that then begins to look quite stable and homeostatic (Scheffer 2009). Certainly the socialecological system we call agriculture is not likely to be an exception.

Leopold's classic essay (1949) has sometimes been held up as a lament that agriculture itself has devastated the natural world. However, even a casual reading reveals that his concern is with the kind of agriculture, not its very existence. He was concerned with how to properly take care of the land, not with eliminating all human activity on it, as is sometimes implied by conservationists. Indeed, he appreciated the way the traditional farmer understood and cared for the land, and lamented the way the new wave of "modernization" was leaving his Sauk County as a sand county. Leopold today would have been quick to note that the collection of agricultural activities that led to a destructive agriculture represented a syndrome, and certainly would have noted the possibility of another set of activities that would have led to what we today refer to as a sustainable system, an alternative syndrome.

These various syndromes of production (Andow and Hidaka 1989) that have existed in the past are, in a sense, precursors of the technological packages offered in the technologically sophisticated modern world. Paddy rice production in Bali has characteristics that are dramatically different from potato farming in the Andes; the total package from socioeconomic organization to pest and soil management constitutes distinct syndromes. Viewed historically, any given spot on the surface of the globe undergoes dramatic regime change from time to time, leading from one pseudo equilibrium to another, from one syndrome to another.

Situated in a particular historical time, it is frequently the case that alternative syndromes coexist, either side by side in a neutral to symbiotic manner (e.g., fish farming integrated with paddy rice production) or in open conflict (farmers versus ranchers on many frontiers). Even when distinct syndromes can be recognized, there are inevitably some commonalities between them, even examples of particular production units that may be intermediate between the two. Furthermore, alternate modes of analysis using eclectic variables frequently obscure underlying patterns, and where alternate syndromes actually exist, their reality may be obscured by such methodological vagaries. 
Arguably there are historical examples and evident future expectations of changes in syndromes. First there is the expectation that independent evolution of particular systems will proceed, and second there is the expectation that distinct syndromes may contribute to the eventual emergence of a hybrid. However, third, and most important, jumps from one syndrome to the other may occur, and indeed may occur rather rapidly and unexpectedly. In the jargon of contemporary ecology, we might expect "regime shifts" happening when "tipping points" are reached.

The current world agricultural situation is remarkably diverse ranging from Amazonian Huaorani harvesting fruits from trees planted by their ancestors (Rival 2002) to the Chiquita ${ }^{\circledR}$ company ordering the U.S. government to negotiate on its behalf at the World Trade Organization (Myers 2004, Witter 2004). Nevertheless one can recognize, or impose, two syndromes that represent extremes in what is a complicated playing field. On the one hand, there has been a tendency for agriculture to become more technified, more mechanized, more chemicalized, more corporate-like, beginning in the nineteenth century and accelerating dramatically since World War II (Robinson and Sutherland 2002). This tendency, born with the Industrial Revolution, has been referred to as "conventional," although a better descriptor would be industrial.

As industrial agriculture was beginning its ascendency, an alternative was brewing. Flush with colonial arrogance, Queen Victoria sent Sir Albert Howard to India in an attempt to help the Indians learn the modern ways of agriculture. Sir Albert, it turns out, was not so naïve. Rather than preaching a paternalistic message about the new scientific agriculture, he focused on observation and learning from local farmers. According to his own testimony:

By 1910 I had learnt how to grow healthy crops, practically free from disease, without the slightest help from ... all the ... expensive paraphernalia of the modern experiment station. (Howard 1940)

We might propose that this event represents the cladistic bifurcation point in which the two main post WWII syndromes of agricultural activities began their relatively independent evolutionary trajectories. On the one hand there are traditional ways of doing things combined with careful observation and farmer-to-farmer interactions, to generate a line of evolution that resulted in an agriculture that uses ecological principles as both stimulus and restriction, to increase and stabilize production. On the other hand we see an ideology of modernization, fueled by a socioeconomic structure that demands returns on investments rather than goals directly related to production. The result is a dichotomy in which most of the farmers in the world do it one way (the "ecological" way) while most of the farmland in the world is devoted to doing it the other way (the "industrial" way). To be sure, one can recognize a continuum between the local organic farm supplying the local farmers' market with fresh fruits and vegetables and the mega corporate landscapes of maize, raked clean with pesticides, fed with synthetic fertilizer, and filling the regional export silos. Yet a random sample of points on the globe would most surely show that a vast number would fall near one of the extremes, presenting us with a bimodal situation. This bimodal distribution represents what are, we contend, two "syndromes" of production (Andow and Hidaka 1989, Vandermeer 1990, 1997).

In the current global political climate it is difficult to engage in discussion of these syndromes without injecting normative content. We admit to our normative preference aimed at the syndrome that gives preference to small-scale agriculture with minimal use of external inputs, supplying local markets as much as possible. However, our intention here is not to argue the merits of that normative position. Rather, we argue for the systematic study of the social-ecological forces that may be important in determining the extant dynamics of change in agriculture. Here we present a qualitative framework upon which we feel a systematic study of agroecosystem socialecological dynamics might be further developed. Our framework is the dynamics of syndromes of production, focusing especially on the way in which syndromes might be transformed.

Recently Scheffer (2009) devised a synthesis that provides a general qualitative background for our framework. At one extreme, if agricultural transformations occurred in an approximately linear fashion with respect to the socialecological determining conditions, a large (or small) change in conditions would imply a large (or small) change in the state of the system (Figure 1a). In such linear processes, the existence of syndromes would certainly be questionable. However, it appears more likely that real systems will show nonlinear responses, such that a small change in conditions might very well result in large changes in the state of the system. Such a nonlinear response would suggest the existence of distinct syndromes (the upper and lower plateaus in Figure 1b).

\section{Dynamic background for syndromes: the case of coffee production}

The coffee agroecosystem provides an illustrative example. Coffee is commonly produced over a range of production techniques ranging from rustic coffee, in which the understory of a natural forest is replaced with coffee bushes, through various forms of shade cover, to the extreme of so-called sun coffee, which is to say coffee monoculture with no shade trees or other plant species (Figure 2; Moguel and Toledo 1999). However, examining the way in which coffee is actually produced in the world suggests bimodality. In Brazil, still the world's largest producer of coffee, sun coffee has been the rule for many years and for all practical purposes all coffee 
Fig. 1. Change in the state of the system as a function of the underlying determining conditions. a. A linear response in which a large change in the system results only from a large change in the conditions. $\mathrm{b}$. A nonlinear response in which a large change in the system may result from only a small change in the conditions (after Scheffer 2009). a.

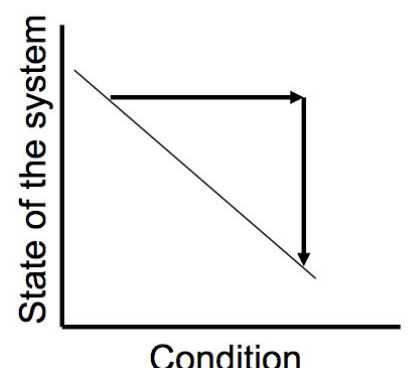

Condition b.

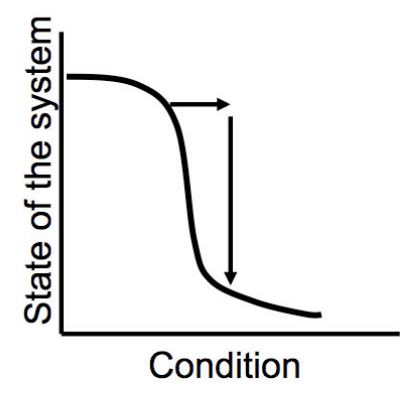

produced in Brazil is sun coffee. This implies that the most common type of coffee production system in the world is sun coffee. Add to Brazil the new expansion of coffee in Vietnam and Indonesia, most of which is sun coffee, and the picture is one of the vast majority of coffee in the world being produced under a sun system. In contrast, the traditional way of coffee production persists in many areas of Latin America, southern India and East Africa. In Central America and Mexico, for example, coffee farms tend to be shaded and in some areas it is difficult to find unshaded coffee at all (e.g., southwestern Mexico), while in other areas coffee farms are distinctly divided into shaded versus unshaded (e.g., Puerto Rico or Colombia). To be sure it is possible to find areas in which one can find a whole range of production techniques (e.g., El Salvador has farms that are heavily shaded, lightly shaded, very lightly shaded, and full sun), but for the most part, when shade coffee has been the tradition, one finds either shade or sun, rarely what would be classified as intermediate. In all systems many varieties of coffee are used. Although the more modern varieties tend to be used more in the sun system, contemporary farms of all sorts use many varieties, including sometimes the incorporation of Coffea canephora within a dominance of Coffea arabica. Despite all these complications, the world distribution of coffee agroecosystems seems to be a bimodal distribution of sun versus shade coffee, with the current situation overwhelmingly biased in favor of sun coffee. An examination of historical transformations in the coffee agroecosystem provides clues to the dynamic processes that have led to this situation of bimodality.

On a visit to coffee farms in the state of Minas Gerais, Brazil, we met a farmer who was convinced to add shade to his sun coffee farm. Based on what one might describe as some questionable advice, he began by planting some fast growing species, not necessarily trees that in other regions were associated with coffee. The coffee plants, perhaps because of their long standing exposure to full sunlight, dropped yields dramatically over the next two years. This, along with some other problems he encountered, convinced this producer that he needed to go back to the security of what he knew well before, a full sun coffee system. Other attempts at converting sun coffee into a shaded system have sometimes met with the same problems (personal conversations with producers in Costa Rica). Thus it seems that if one is currently involved with producing coffee under a full sun system, moving to a shade system is not easy, and attempts to do so might very well be met with barriers related to a lack of knowledge about the management of the shade, the appropriate tree species to intercrop with coffee, and a variety of other technical and socioeconomic issues. If these barriers are not quickly overcome, the farmer will feel a need to return to the sun system, as happened with the farmer we met in Brazil. In other words, the lower plateau (taking the sun coffee system to be represented by the lower plateau) illustrated in Figure $1 \mathrm{~b}$ is something of a stable situation and deviations from it are countered by regression to it.

Consider the other extreme. Experience in attempting to move a shaded farm to a sun farm can be equally daunting for a producer. For example, in one case in southern Mexico a farmer interested in increasing the productivity on his farm

Fig. 2. The range of coffee production systems in Mexico. Ordinate on each graph is in meters. Redrawn from Moguel and Toledo 1999.

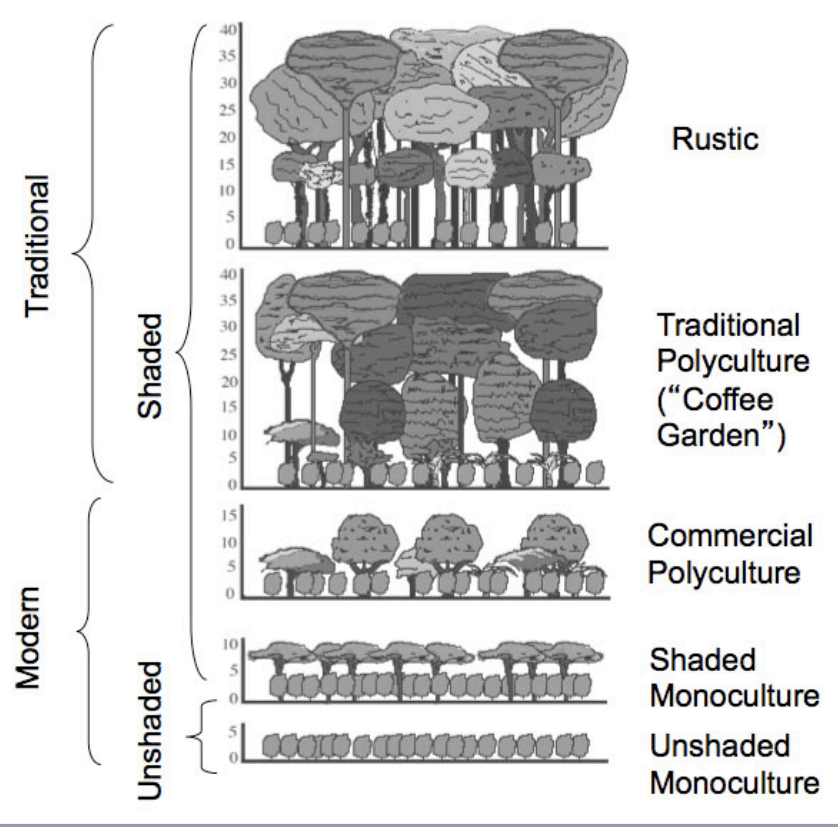


began removing the shade, but quickly discovered that production declined dramatically due to excessive weed growth. Having invested a great deal of money for labor to cut the shade, he had little left to pay labor costs for cutting the weeds, so he had to move to a herbicide, which was a dramatic risk since the farm was certified organic, and had he been caught with this nonorganic technique, the premium he was counting on for the organic product would be lost. As risky as it was, he felt he needed to control the weeds but he could not afford the labor cost, so he decided to go with the herbicide, perhaps thinking it would only be a onetime temporary activity. But then he discovered that he could not afford the desired product, and was forced to purchase a lower priced product, which turned out to be not nearly as effective, and at last sight he was facing massive drops in yields. Clearly, such a series of events would convince many producers to return to the shaded system. Many other aspects of the way a shaded system functions, from provisioning nitrogen from leguminous shade trees (Glover and Beer 1986), to autonomous pest control from the embedded biodiversity in the system (Vandermeer et al. 2010), will be slowly lost as the move away from shade is pursued. Many times this will suggest to the farmer that going back to the shaded system is the best strategy. In other words, the upper plateau illustrated in Figure $1 \mathrm{~b}$ is also something of a stable situation and deviations from it are countered by regression to it.

We believe this example of coffee production is repeated in other agroecosystems. Perhaps there are multiple syndromes, or perhaps it would benefit understanding if we were to conceive of them as multiple, but as a starting point constructing a dual classification is useful, not only for coffee agroecosystems, but for agroecosystems in general. Such a classification already exists in the mind of most analysts, of many different persuasions. The normative judgment as to which syndrome is best is wildly divergent, but there seems to be agreement that two syndromes indeed coexist, especially after World War II (WWII). On the one hand there is smallscale agriculture, usually connected to some sort of family or extended family structure. It is regarded by some as inefficient and anachronistic, by others as productive and ecologically sustainable. It is by actual calculations, more productive on a per unit area basis (Carter 1984, Cornia 1985, Binswanger et al. 1995, Heltberg 1998), and frequently more energy efficient (Pimentel et al. 1983, 2005) than its alternative, but, by modern economic standards, frequently far less labor efficient and less profitable (Sen 1962, Hanson et al. 1997). On the other hand there is industrial agriculture, having gone through a variety of stages since Victorian times (Holt-Giménez and Shattuck 2011), but taking on its present form subsequent to the ideological reforms in the wake of WWII (Russell 2001). It is regarded by some as efficient and modern (Avery 2000), by others as wasteful and ecologically unsustainable (International Assessment of Agricultural Knowledge,
Science and Technology for Development 2009). Our analysis does not attempt to demonstrate that the two syndromes exist; we take that as evident from simple observation and universally accepted opinion. Our argument is that these two syndromes represent dynamically stable alternatives. Our intent is to formulate a generalized framework that can help in the pursuit of understanding how those dynamics operate at the present moment.

\section{Contemplating the dynamics: a simple model}

It is standard in most scholarly pursuits to begin with a simple framing that encapsulates what is thought to be the essence of the problem. That is what we attempt to do here. However, in the present circumstance we insist that at its most fundamental core, the dynamics of agroecosystem transformation include both socioeconomic and ecological forces. Consequently, the most elementary framework is, of necessity, somewhat less elementary than its cousins in either economics or ecology, since it must include both forces.

Although we are aware that many farmers, (e.g., indigenous people in the Global South) are not directly connected to markets, our analysis applies to farmers that are in some way connected to markets, either local or global. On the economic side we assume the standard framework that the amount of a commodity indirectly determines the price paid for that commodity and that producers of that commodity will produce more of it in response to consumers being willing to pay more (see any elementary microeconomics text, for example, Mankiw 2011). Since we are dealing with agriculture, this standard framework plays out in noncontinuous time; farmers plant and harvest at discrete points in time and harvest necessarily occurs some time after planting. Thus we propose the very simplified model framework,

$$
\begin{aligned}
& P_{t+1}=f\left(A_{t}\right) \\
& A_{t+1}=g\left(P_{t}\right),
\end{aligned}
$$

where $P_{t}$ is the price of the commodity at time $t, A_{t}$ is the amount of the commodity offered to the market at time $t, f$ is the rule that translates $\mathrm{A}$ into $\mathrm{P}$ and $\mathrm{g}$ is the rule that translates $\mathrm{P}$ into $\mathrm{A}$. Note that the functions $\mathrm{f}$ and $\mathrm{g}$ do not have to be linear, and, we argue, generally will not be linear. The amount produced at time $t+2$ is easily calculated by composing the two functions, giving (Vandermeer 1997):

$$
A_{t+2}=g\left[f\left(A_{t}\right)\right] .
$$

On the ecological side recent literature acknowledges a variety of forms, most of which are sufficiently similar to one another that we may contend they are effectively the same. It is common to speak of ecosystem engineers in which some part of the environment is constructed by organisms, the engineers (Cuddington et al. 2007). Recent literature finally recognizes 
the persistent insistence of Lewontin that organism and niche are dialectically related to one another (Lewontin 1991) and the phenomenon of niche construction becomes an ecological and evolutionary force (Odling-Smee et al. 2003, Vandermeer 2008, 2009). Alternately, more traditionally, competition theory recognizes that some organisms effect changes in the environment to which they and other organisms must respond. What all of these ideas mean in terms of agricultural production is that the amount that is produced of a particular commodity is a function of the ecological conditions in which it is produced, but the amount produced, in turn, affects those ecological conditions. This may be framed, in discrete time as:

$$
\begin{aligned}
& A_{t+1}=h\left(E_{t}\right) \\
& E_{t+1}=m\left(A_{t}\right),
\end{aligned}
$$

where $A_{t}$ is the same as in equation $2, E_{t}$ represents the ecological conditions at time $\mathrm{t}, \mathrm{h}$ is the rule that translates $\mathrm{E}$ into $\mathrm{A}$ and $\mathrm{m}$ is the rule that translates $\mathrm{A}$ into $\mathrm{E}$. With a similar composition we can write:

$$
A_{t+2}=h\left[m\left(A_{t}\right)\right]
$$

It might be argued that equation 2 is the simplest form that one might envision an agricultural socioeconomic system. It is without doubt far too simple to describe in any precise way what the system is about, but its general form provides us with an underlying "frictionless" framework upon which to build more realistic and precise frameworks. But in addition to providing that frictionless framework, it provides us with a certain amount of understanding of what might be expected in the socioeconomic world of agriculture. The basic supply and demand framework of microeconomics contains this fundamental idea and has certainly been a useful starting point for the theory of the firm (Mankiw 2011). In the same vein equation 4 is certainly not a realistic or precise representation of ecological engineering or niche construction or any other way in which the environment is modified by and in turn modifies organisms, in this case crops and livestock. But it too provides us with an underlying conceptual framework that relates ecological forces with agricultural production. We add that the presentation of the model in its most general form is in the tradition of stipulating a model that has universal applicability given the underlying mathematical constraints. Further stipulation of particular conditions is quite unnecessary since any real world conditions that satisfy the particular assumptions of the model, which have been presented here, with additional constraints described in the text that follows, will give the same results. Thus, for example, we presume the functions are continuous and differentiable and we add that at least one of them (it does not matter which) is nonlinear, otherwise the results are trivially linear.
Yet in the present work our goal is to retain the level of simplicity and generalization commonly assumed with formulations such as equations 2 and 4, but incorporate the fundamental realism that agroecosystem dynamics indeed always include both ecological and socioeconomic forces. Thus, we not only accept the utility of the approaches stipulated by 2 and 4, we insist that the minimal model must include both of them. Our minimal model then, is the composition of equations 2 and 4 . Combining 2 and 4 (Vandermeer 1997), we obtain:

$$
A_{t+4}=h\left[m\left\{g\left[f\left(A_{t}\right)\right]\right\}\right]=Q\left(A_{t}\right)
$$

By inspection, as long as at least one of the functions (h, m, $\mathrm{g}$, or $\mathrm{f}$ ) is nonlinear, the generalized function $\mathrm{Q}$ will be nonlinear. Furthermore, if two or more of these functions are nonlinear the prospect for alternative nonzero solutions arises, which is to say alternative syndromes.

As a simplified initial model, equation 5 is useful to explore the way in which the "conditions" determine the "state of the system" (Figure 1). In Figure 3 we illustrate the generalization of how equation 5 stipulates the conditions that in turn determine the state of the system. Here we see the basic simple idea that a smooth change in dynamic rules will lead to a relatively smooth transition from state to state in the system. The basic idea that a linear approach results in obtaining large changes in state only from a large change in conditions is clearly reflected in this framework, although not specifically in Figure 3. However, other more complicated consequences also emerge quite naturally from this simple model, such as alternative syndromes and hysteresis.

The various dynamic consequences of nonlinear $Q$ are explored in considerable detail in Vandermeer (1997). For here suffice it to say that alternative equilibria emerge quite easily. For example, this occurs when economic planning on an individual level leads to overproduction and price collapse while simultaneously ecological pressure from the overproduction leads to environmental degradation; the two alternative states are then chronically low prices with environmental degradation versus stable high prices with benign environmental effects (explained more fully in Vandermeer 1997). It is also the case that the phenomenon of hysteresis is a common feature if the nonlinearities become strong, as illustrated in Figure 4. The latter structure suggests that previous patterns of change cannot simply be reversed with the expectation of system reversion under the same conditions. Also it is evident upon inspection that changing the nonlinear nature of the function can easily produce complicated chaotic behavior, which sets up the possibility of dramatic regime shift either through a small change in a parameter, as illustrated in Figure 5a, or simply from the boundary of a chaotic attractor intersecting the separatrix of 
Fig. 3. Change in the conditions as a function of the simple dynamic model, $\mathrm{A}_{\mathrm{t}+4}=\mathrm{h}[\mathrm{m}\{\mathrm{g}[\mathrm{f}(\mathrm{At})]\}]$. We assume nonlinear response for at least one of the functions in the composed function.

a. Repeat of Figure $1 \mathrm{~b}$ with the colored equilibrium points corresponding to the colored functions in part $b$ (where the function crosses the 45 degree line is an equilibrium point).

b. Four examples of the dynamic model, color coded to correspond to the colors of the equilibria in part a. The abcissa is the initial state of the system (this could be either commodity price or amount produced) and the ordinate represents the state of that system four projections into the future. The 45 degree line represents the locus of points for which there will be no change over the four unit projection, thus an equilibrium point is located where the function crosses that line.
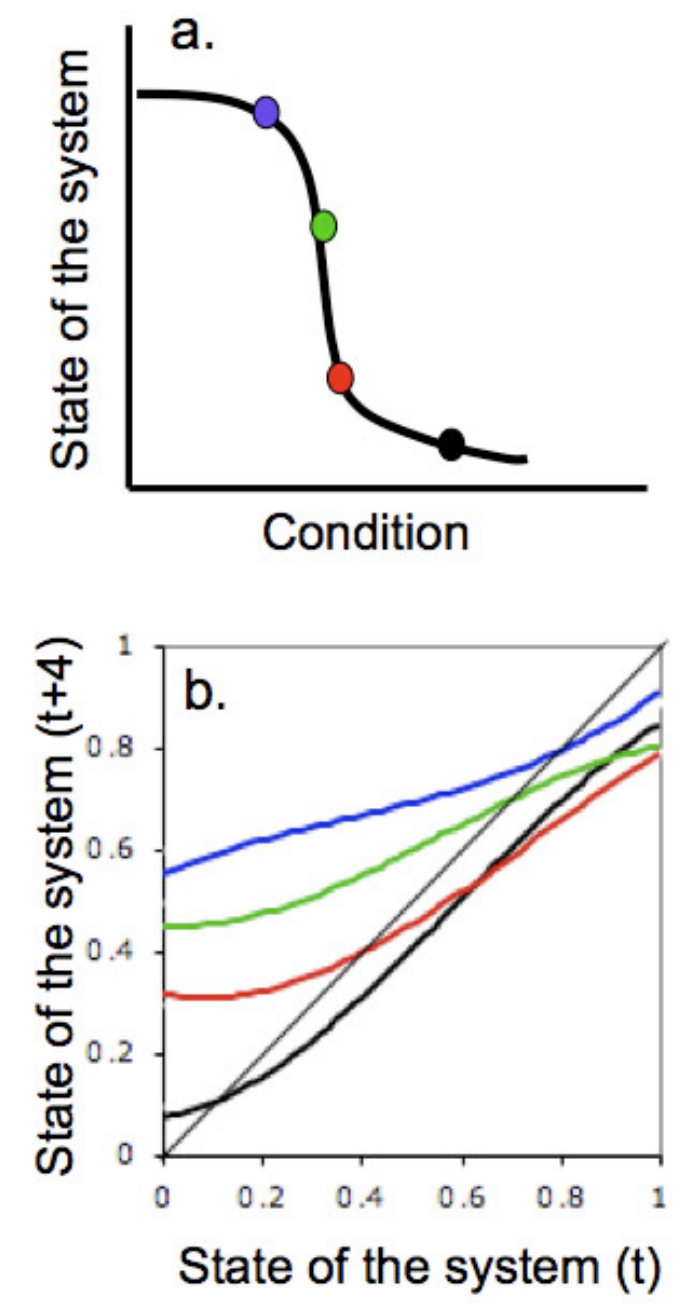
The general result from this model is that regime changes, or shifts in syndromes, arise naturally and easily from the simplest of assumptions about the relationship between prices and production. We also note that the general idea of syndromes of production and switching among them is likely more general than confined to this economic/ecological model, as we illustrate in the next section with a distinct framework.

\section{An approach through human population dynamics and niche construction}

The idea of niche construction, very similar conceptually to the idea of ecological engineering, has become influential in evolutionary biology. Its impact on ecological thinking is less evident (Vandermeer 2008). The classic metaphor to explain the ecological form of the idea is the beaver and the beaver pond. The niche of the beaver is the beaver pond, but the beaver constructs the beaver pond by making a dam. Thus there is a dialectical relationship between organism and its niche.

Fig. 5. Relaxing the monotonic assumption of the relation between conditions and state of the system. The red and blue parts of the curve represent the location of stable points, and the red and blue lines near the abscissa represent the basins of attraction for the two stable point configurations, according to either red or blue.

a. Possibility of catastrophic shift in syndrome resulting from a small change in conditions, due to the basic hysteretic framework. If the system is located at either of the initial positions of either of the arrows, a very slight change in the conditions will result in a sudden shift of the system from one syndrome to the other.

b. Possibility of sudden change in syndrome due to basin boundary collision, or the crossing of a basin separatrix through stochastic processes (the red shading indicates the zone of chaotic or quasiperiodic behavior or stochastic variation). If the red zone intersects the edge of the part of the curve that bends over, eventually the system will jump from one syndrome to the other. Note that this kind of jump does not require any change in the conditions at all. a.

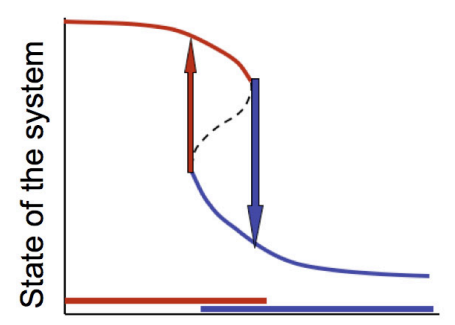

Condition b.

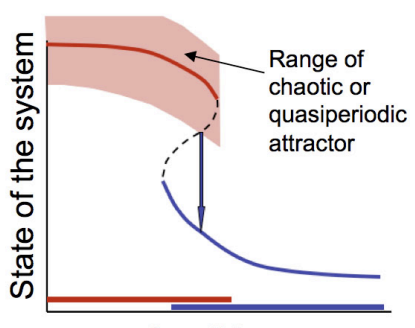

Condition
Fig. 6. Overall summary of expected qualitative behavior of an agroecosystem with changing conditions (as stipulated by the simple dynamic model), the degree of nonlinearity of the model, and the resultant syndrome of production (i.e., state of the system). The point at which the function loses its monotonicity is referred to as a codimension 2 bifurcation.

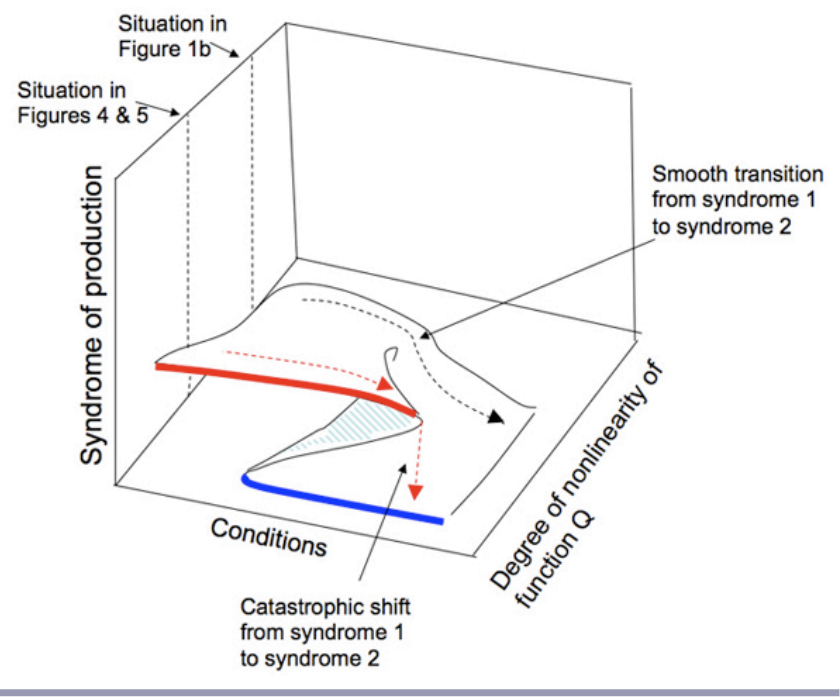

This conceptual framework is especially useful in framing agricultural change (Perfecto and Vandermeer 2010, Vandermeer 2009). A particular agricultural technology stipulates two population parameters: the necessary population and the sustainable population. The metaphor works best when thinking of nonindustrial types of technology, such as terracing or informal irrigation, although we believe it applies roughly to all agricultural transformations. A certain number of people would be needed to first construct the terraces and then to maintain them. The terraces represent a stage in agricultural technology, a syndrome. But it is also obviously the case that with the terraces in place, more people could be sustained in the population than before the terraces were built.

The necessary population is the number of people needed to maintain the agricultural technologies and the sustainable population is the number of people that can be sustained on the production that comes out of that technology. If the actual number of people in the population is less than the necessary number, there is a labor shortage. If the actual number of people in the population is greater than the sustainable number, there is a food shortage. Consequently there is a dynamical system operative. When food is short the tendency will be to increase production, which means increase the level of technology, which means the necessary population will be compelled to increase. The basic rules can be formulated unambiguously with two state variables, $\mathrm{N}$, the population size and $\mathrm{E}$ the technology employed (environment, broadly 
speaking). There are two subcategories of the population, the necessary population $\mathrm{N}_{\mathrm{E}}$ and the sustainable population $\mathrm{N}_{\mathrm{S}}$, both of which of necessity increase (but not necessarily monotonically) with increase in technology. Thus, we may write:

$$
\begin{aligned}
& N_{E}=f(E) \\
& N_{S}=g(E)
\end{aligned}
$$

This effectively stipulates the equilibrium situation of a dynamic model (e.g., a set of differential equations). Each of the equations represents the equilibrium state of the system as a function of the technology (E). Thus, they can be thought of as the isoclines of the dynamic model:

$$
\begin{aligned}
& \frac{d E}{d t}=N-g(E) \\
& \frac{d N}{d t}=f(E)-N
\end{aligned}
$$

Note that an isocline refers to the set of points for which there is no change in the variable in question and is generally found in a dynamic model by setting the derivatives equal to zero and solving algebraically for the variables of interest.

The functions $\mathrm{f}$ and $\mathrm{g}$ will generally, but not always, be increasing functions of $\mathrm{E}$. The qualitative dynamics of the system are illustrated in phase space in Figure 7. If the functions $f$ and $g$ were simple linear functions, the way they cross indicates whether or not the system will form a stable situation; the particular example in Figure 7a is stable. It is not difficult to imagine various nonlinearities involved, in which case alternative equilibria are distinct possibilities. In Figure $7 \mathrm{~b}$ we illustrate the case in which two alternative equilibria emerge from the nonlinear response of the sustainable population to the conditions of production (the "environment"). The two stable points are separated by an unstable point (a saddle point), which divides the entire space into two basins of attraction, shown by the dotted lines on each of the axes. Details of this model can be found elsewhere (Vandermeer 2008, 2009). Suffice it to note here that depending on the exact shape of the functions $f$ and $g$, one can generate a situation in which the population remains balanced between the tendency to increase technology and the tendency to increase population and when deviating from that balance tends to return to it; yet for distinct ecological and social underlying conditions, the balance itself is unstable, leading to either runaway population growth or technological decay.

Of particular interest for the present work is the case in which the assumption of monotonicity is relaxed. For example, it might be that increases in the conditions of production (the environment) reach a point at which further increases generate
Fig. 7. Population dynamic model of agricultural regime shifts.

a. Assuming a simple linear relationship between the environment (which is, in this context actually a technology of production) and the population density. Because of the way the sustainable curve crosses the necessary one, the equilibrium is stable. If the crossings were to be reversed, the point would be unstable.

b. Making the sustainable curve nonlinear results in two alternative equilibria separated by a saddle point. The dotted lines indicate the basins of attraction of the two equilibria (From Vandermeer 2009).
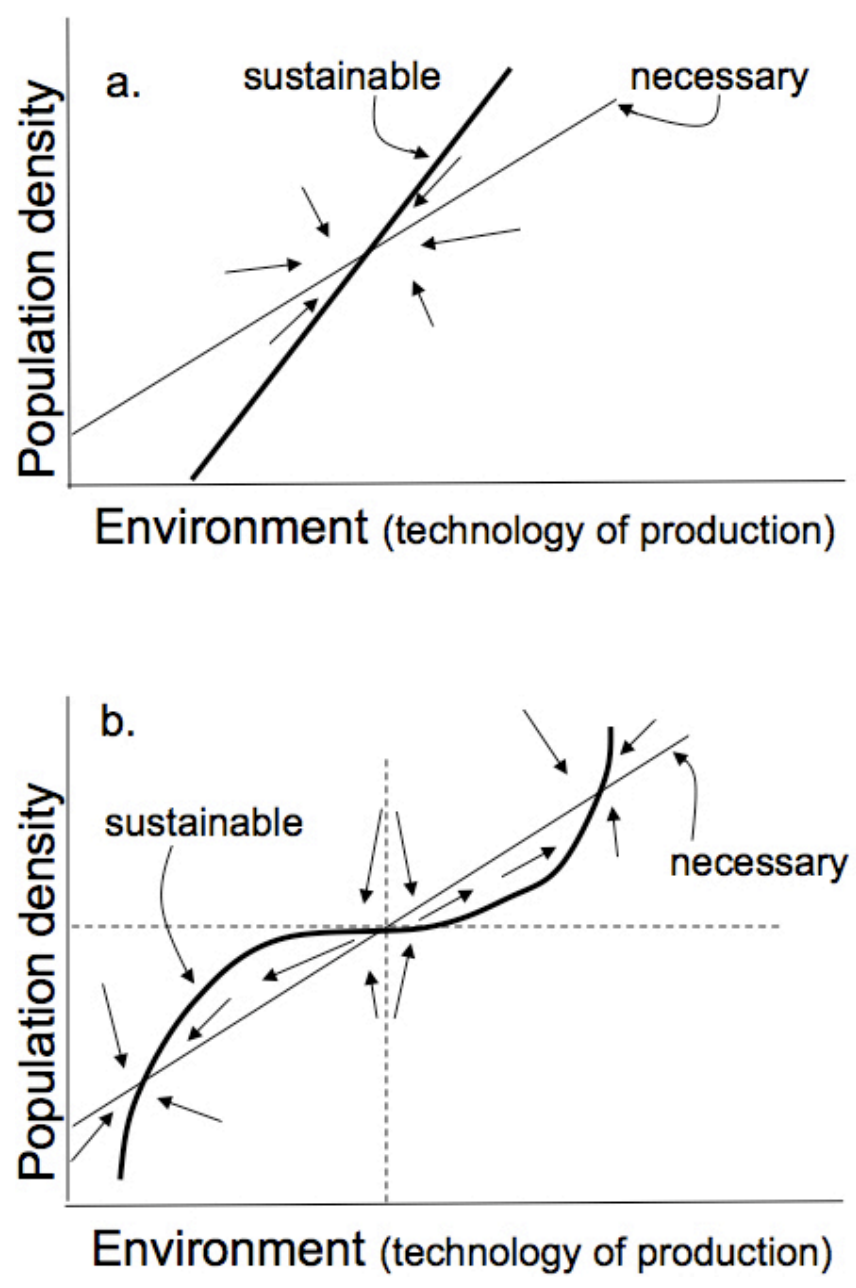

a decline in the sustainable population, as suggested in Figure $8 \mathrm{a}$ (the double arrow noting the zone of "intermediate unfavorable technology"). However, it could be that social customs or economic vicissitudes dictate that further increases in those conditions continue (i.e. the function $\mathrm{g}(\mathrm{E})$ is 
nonmonotonic), for a short range of further increases in production conditions. Such would be the case if, for example, the population was convinced that as production conditions increased, there would be a time period in which things would get worse for agricultural production, but future prospects suggest an eventual dramatic increase; the population buys into the idea of a future reward for present sacrifice and pushes ahead with further technological advancement. Such a situation is illustrated by the red curve in Figure $8 \mathrm{a}$. As can be seen in that figure, the upper equilibrium will be reached if, at a particular population density, the conditions are such that point number 1 is the situation. However, if point number 2 is the reality, the lower equilibrium will be reached, from that same population density. Using population density as the "condition", we see how this framework yields the same nonmonotonic relationship between conditions and syndrome in Figure 8b (recall Figure 4).

Thus we see once again that the potential for regime changes, or shifts in syndromes, arises naturally and easily from the simplest of assumptions.

\section{DISCUSSION}

We propose that the conditions under which agricultural syndromes of production change can be thought of as a complex social-ecological system that generates its own dynamics. We present a very simplified modeling approach that incorporates both ecological and socioeconomic forces, not as an attempt to portray what happens in a precise fashion, but rather to suggest broad features of dynamic expectations that might emerge from the nonlinear nature of the socialecological formulation. Indeed the "conditions" we envision ultimately include management strategies, land tenure, economic structures, political structures, climate, soil fertility, natural enemies and pests in the system, amount of mycorrhyzal fungi, and a host of other complex and interpenetrating factors. Our simple model is intended to suggest the minimal level of complexity that should be expected from the complex conditions involved in changing syndromes.

Although the sense of our framework is intended to apply to contemporary or recent agricultural syndromes, there is nothing in its elaboration that immediately excludes its application to more remote situations. For example, the transition from hunting and gathering to agriculture likely involved the interplay of ecological and socioeconomic factors. Better radiocarbon dating and paleoclimatic interpretations suggest that the sudden change of the Natufians from hunters and gatherers to agriculturalists was the result of such interplay (Weiss and Bradley 2001). The open oak woodlands and wild cereals that were exploited by the Natufians in the Levant and northern Mesopotamia changed dramatically and abruptly with the initiation of the Younger Dryas 12,900 years ago (Moore and Hillman 1992). The cooler and drier climatic conditions likely affected the production of wild cereals to the point that gathering alone was not enough to provide sustenance to the Natufians, forcing a relocation of settlements to areas where cultivation of the cereals was possible (Hole 1998, Bar-Yosef 2000). Permanent location and agriculture also require dramatic socioeconomic changes including changes in the division of labor and work schedule seasonality. Furthermore, to engage in agricultural production they needed a large enough population to be able to plant and maintain the fields (i.e., the necessary population). But the more stable provision of food that resulted from cultivation resulted in higher fertility (and therefore a higher sustainable population) and consequently population growth (Bentley 1996). This interplay of ecological and socioeconomic factors created the conditions for a dramatic change in the syndrome of production, which was key in consequent social evolution (Weiss and Bradley 2001).

In more modern times we have examples in which a decrease in the local population caused a clear shift in the syndrome. For example, the system of oak and truffles (Pierre 2009) is a syndrome that was maintained for generations through grazing and fire management. Then, beginning at the turn of the $20^{\text {th }}$ century and accelerated due to the military needs of WWI,

Fig. 8. Population dynamics model of agricultural regime shifts.

a. Making the sustainable curve (see Figure 5), nonmonotonic. If the population density is at the dotted line that is intercepted by either point 1 or point 2 , either the higher or lower equilibrium could be reached. Which equilibrium actually is attained depends on where the system is on the other axis, such that point 1 will move to the higher equilibrium, and point 2 will move to the lower equilibrium.

b. Representing the graph in a. with the axes reversed and plotting the equilibrium values. The dotted curve is superimposed illustrating that the results of the model are qualitatively the same as the previous model with alternative equilibria and a zone of hysteresis.

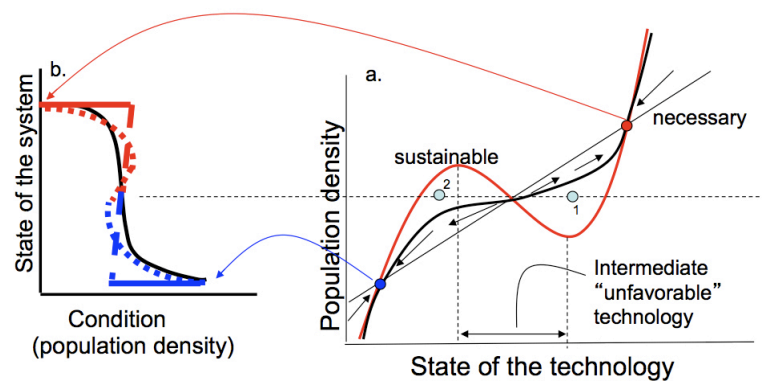


outmigration of the local population caused a crisis in available labor, which meant that the population density necessary for maintaining the savannah tipped below a critical point, and the oak savannah gave way to secondary succession and the rapid loss of this highly productive system. Furthermore, its recuperation seems to have conformed to the classic notion of hysteresis. A similar situation has been reported in more recent times in the Las Lagunas Valley of Mexico (Garcia Barrios and Garcia Barrios 1990), in which an agroecosystem based on terracing and other sophisticated traditional methods was effectively destroyed (a major and rapid syndrome shift) due to a sudden outmigration caused by employment opportunities elsewhere. The lack of labor to maintain the terraces combined with the steep slopes and fragile soils of the region to cause a collapse of a highly sophisticated traditional system of production.

In the growing literature on regime change in ecology (e.g., Scheffer et al. 2009) a common theme is the search for indicators of impending regime change. A variety of suggestions ranging from changes in spatial pattern to "critical slowing down", have appeared. Although the present communication is not intended to contribute to that discourse, it is worth noting that when applied to agroecosystems such a search has precedent in the search for sustainability indices (Astier et al. 2009). Empirically there are a variety of measurement strategies that purport to be indicators that sustainability is in the process of being attained. If, as we suggest, the moniker sustainability represents a syndrome of agroecosystems, these previous studies may represent the early warning signs that such a syndrome is imminent. Naturally, the negation of those indicators may indicate that a reverse regime change is on the way.

The history of agriculture is filled with examples of sudden or relatively rapid changes in syndromes of production. In many cases these systems appeared to be stable systems until something happened to generate a tipping point that led to an alternate stable state. At times the push comes from changes in the ecological conditions, other times it comes from socioeconomic changes, yet other times it comes from the interplay between the two. However, regardless of what factors generate the tipping point, understanding the process of change in the syndromes of production requires the incorporation of both ecological and socioeconomic factors. Here we develop a generalized model using the minimal dynamical ecological and socioeconomic rules of production and find that with a mere relaxation of linearity assumptions alternative syndromes with the potential for regime changes are easily generated. These results correspond, at least qualitatively, with historical observations of changes in syndromes of production and suggest a way of envisioning possible future changes.
Responses to this article can be read online at: http://www.ecologyandsociety.org/issues/responses. php/4813

\section{Acknowledgments:}

We thank two anonymous reviewers and the many coffee farmers who shared their farming experiences that inspired this analysis.

\section{LITERATURE CITED}

Andow, D. A., and K. Hidaka. 1989. Experimental natural history of sustainable agriculture: syndromes of production. Agriculture, Ecosystems and Environment 27:447-462.

Astier, M., O. Masera, and Y. Galván. 2009. Evaluación de sustentabilidad: un enfoque dinámico y multi-dimensional. Centro de Investigaciones de Geografía Ambiental, Universidad Nacional Autónoma de México (CIGA_UNAM); Centro de Investigaciones de Ecosistemas, Universidad Nacional Autónoma de México (CIEco-UNAM); El Colegio de la Frontera Sur (ECOSUR); Grupo Interdisciplinario de Tecnología Rural Apropriada, Asociación Civil (GIRA- AC). Sociedad Española de Agricultura Ecológica (SEAE), Mexico.

Avery, D .T. 2000. Saving the planet with pesticides and plastic: the environmental triumph of high-yield farming. Hudson Institute, Washington, D.C., USA.

Bar-Yosef, O. 2000. The impact of radiocarbon dating on Old World archeology: past achievements and future expectations. Radiocarbon 42:23-29.

Beddoe, R., R. Costanza, J. Farley, E. Garza, J. Kent, I. Kubiszewski, L. Martinez, T. McCowen, K. Murphy, N. Myers, Z. Ogden, K. Stapleton, and J. Woodward. 2009. Overcoming systemic roadblocks to sustainability: the evolutionary redesign of worldviews, institutions, and technologies. Proceedings of the National Academy of Science 106:2843-2489. http://dx.doi.org/10.1073/pnas.0812570106

Bentley, G. R. 1996. How did prehistoric women bear "Man the Hunter"? Reconstructing fertility from the archaeological record. Pages 23-51 in R. P. Wright, editor. Gender and archaeology. University of Pennsylvania, Philadelphia, Pennsylvania, USA.

Binswanger, H. P., K. Deininger, and G. Feder. 1995. Power, distortions, revolt and reform in agricultural land relations. Pages 2659-2772 in J. Behrman, and T. N. Srinivasan, editors. Handbook of development economics. Volume 3A. Elsevier, Amsterdam, The Netherlands. 
Braudel, F. 1984. Civilization and capitalism, 15-18 $8^{\text {th }}$ century. Harper Collins, New York, New York, USA.

Carter, M. R. 1984. Identification of the inverse relationship between farm size and productivity: an empirical analysis of peasant agricultural production. Oxford Economic Papers 36:131-145.

Cornia, G. A. 1985. Farm size, land yields and the agricultural production function: an analysis for fifteen developing countries. World Development 13:513-534. http://dx.doi. org/10.1016/0305-750X(85)90054-3

Cuddington, K., J. E. Byers, W. G. Wilson, and A. Hastings. 2007. Ecosystem engineers: plants to protists. Academic Press/ Elsevier, Amsterdam, The Netherlands.

Garcia-Barrios, R., and L. Garcia-Barrios. 1990. Environmental and technological degradation in peasant agriculture: a consequence of development in Mexico. World Development 18:1569-1585. http://dx.doi.org/10.1016/0305-750X (90)90044-X

Glover, N., and J. Beer. 1986. Nutrient cycling in two traditional Central American agroforestry systems. Agroforestry Systems 4:77-87.

Hanson, J. C., E. Lichtenberg, and S. E. Peters. 1997. Organic versus conventional grain production in the mid-Atlantic: an economic and farming system overview. American Journal of Alternative Agriculture 12:2-9. http://dx.doi.org/10.1017/ $\underline{\text { S0889189300007104 }}$

Heltberg, R. 1998. Rural market imperfections and the farm size-productivity relationship: evidence from Pakistan. World Development 26:1807-1826. http://dx.doi.org/10.1016/S0305-750X (98)00084-9

Hole, F. 1998. The spread of agriculture to the eastern arc of the Fertile Crescent: food for the herders. Pages 83-92 in A. B. Damania, J. Valkoun, G. Willcox, and C. O. Qualset, editors. The origins of agriculture and crop domestication. International Center for Agricultural Research in the Dry Areas (ICARDA), Aleppo, Syria.

Holt Giménez, E., and A. Shattuck. 2011. Food crises, food regimes and food movements: rumblings of reform or tides of transformation? Journal of Peasant Studies 38:109-144. http://dx.doi.org/10.1080/03066150.2010.538578

Howard, A. 1940. An agricultural testament. Oxford University Press, Oxford, UK.

International Assessment of Agricultural Knowledge, Science and Technology for Development (IAASTD). 2009. Agriculture at a crossroads. Synthesis report. Island Press, Washington, D.C., USA.

Leopold, A. 1949. A Sand County almanac and sketches here and there. Oxford University Press, Oxford, UK.
Lewontin, R. 1991. Biology as ideology: the doctrine of DNA. Harper Collins, New York, New York, USA.

Mankiw, N. G. 2011. Principles of economics. Sixth Edition. South-Western Cengage Learning, Mason, Ohio, USA.

Moguel, P., and V. M. Toledo. 1999. Biodiversity conservation in traditional coffee systems of Mexico. Conservation Biology 13:11-21. http://dx.doi.org/10.1046/ j.1523-1739.1999.97153.x

Moore, A. M. T., and G. C. Hillman. 1992. The Pleistocene to Holocene transition and human economy in southwest Asia: the impact of the Younger Dryas. American Antiquity 57:482-494. http://dx.doi.org/10.2307/280936

Myers, G. 2004. Banana wars: the price of free trade, a Caribbean perspective. Zed Books, London, UK.

Odling-Smee, F. J., K. M. Laland, and M. W. Feldman. 2003. Niche construction: the neglected process in evolution. Princeton University Press, Princeton, New Jersey, USA.

Perfecto, I., and J. Vandermeer. 2010. The agroecological matrix as alternative to the land-sparing/agriculture intensification model. Proceedings of the National Academy of Science 107:5786-5791. http://dx.doi.org/10.1073/pnas.0905455107

Pierre, S. 2009. The truffle and its cultivation in France. Acta Botanica Yunnanica, Supplement XVI 72-80.

Pimentel, D., G. Berardi, and S. Fast. 1983. Energy efficiency of farming systems: organic and conventional agriculture. Agriculture, Ecosystems and Environment 9:359-372. http:// dx.doi.org/10.1016/0167-8809(83)90021-X

Pimentel, D., P. Hepperly, J. Hanson, D. Douds, and R. Seidel. 2005. Environmental, energetic, and economic comparisons of organic and conventional farming systems. BioScience 55:573-582. http://dx.doi.org/10.1641/0006-3568(2005)055 [0573:EEAECO]2.0.CO;2

Rival, L. M. 2002. Trekking through history: the Huorani of Amazonian Ecuador. Columbia University Press, New York, USA.

Robinson, R. A., and W. J. Sutherland. 2002. Post-war changes in arable farming and biodiversity in Great Britain. Journal of Applied Ecology 39:157-176. http://dx.doi.org/10.1046/ j.1365-2664.2002.00695.x

Russell, E. 2001. War and nature. Cambridge University Press, Cambridge, Massachusetts, USA.

Scheffer, M. 2009. Critical transitions in nature and society. Princeton studies in complexity. Princeton University Press, Princeton, New Jersey, USA.

Scheffer, M., J. Bascompte, W. A. Brock, V. Brovkin, S. R. Carpenter, V. Dakos, H. Held, E. H. van Nes, M. Rietkerk, 
and G. Sugihara. 2009. Early warning signals for critical transitions. Nature 461:53-59.

Sen, A. K. 1962. An aspect of Indian agriculture. The Economic Weekly Feb.:243-246.

Vandermeer, J., I. Perfecto, and S. Philpott. 2010. Ecological complexity and pest control in organic coffee production: uncovering an autonomous ecosystem service. BioScience 60:527-537. http://dx.doi.org/10.1525/bio.2010.60.7.8

Vandermeer, J. 1990. Notes on agroecosystem complexity: chaotic price and production trajectories deducible from simple one-dimensional maps. Biological Agriculture \& Horticulture 6:293-304. http://dx.doi.org/10.1080/01448765$\underline{1990.9754529}$

Vandermeer, J. 1997. Syndromes of production: an emergent property of simple agroecosystem dynamics. Journal of Environmental Management 51:59-72. http://dx.doi.org/10.1006/ jema.1997.0128

Vandermeer, J. 2008. The niche construction paradigm in ecological time. Ecological Modeling 214:385-390. http://dx. doi.org/10.1016/j.ecolmodel.2008.03.009

Vandermeer, J. 2009. The ecology of agroecosystems. Jones and Bartlett, Sudbury, Massachusetts, USA.

Vandermeer, J., and P. Yodzis. 1999. Basin boundary collision as a model of discontinuous change in ecosystems. Ecology 80:1817-1827. http://dx.doi.org/10.1890/0012-9658(1999) 080[1817:BBCAAM]2.0.CO;2

Wallerstein, I. 2001. Braudel and interscience: a preacher to empty pews? Review (Fernand Braudel Center) XXIV (1):3-12. [online] URL: http://www2.binghamton.edu/fbc/ archive/iwjb.htm

Weiss, H., and R. S. Bradley. 2001. What drives societal collapse? Science 291:609-610. http://dx.doi.org/10.1126/ science. 1058775

Witter, M. 2004. Yes we sell no bananas. Harvard International Review 26:84-85. 